SVU- International Journal of Veterinary Sciences, 2 (2): 101-110, 2019.

Print ISSN: 2535-1826

\title{
Anatomical Descriptions of the Nasal Cavity of the Aquatic and Non-Aquatic Birds
}

Fatma A. Madkour*1

${ }^{1}$ Department of Anatomy and Embryology, Faculty of Veterinary Medicine, South Valley University, Qena 83523, Egypt

\begin{abstract}
This study attested the anatomical and morphometrical descriptions of the nasal cavity in duck, goose as the aquatic birds and quail, dove as the non-aquatic birds. This study elucidated in the aquatic birds that the nasal cavity remarkable increased in width caudally and had relatively larger nasal conchae and greater of the middle nasal concha than the non-aquatic birds. The nostrils without operculum in the aquatic birds and with horny operculum in the non-aquatic birds, it located at the base of the upper beak by variable distances but in quail, it located punctually at the base of the beak. In all examined birds, the nasal cavity consisted of three nasal conchae except dove consisted of two conchae. The middle nasal concha length constituted the highest percentage to that of the nasal cavity which was recorded $63.91 \%, 55.18 \%$, and $58.88 \%$ in duck, goose and quail respectively except in dove the caudal one recorded the highest percentage $42.16 \%$. In transverse sections, the rostral nasal concha projected from the lateral wall of the nasal cavity as a shelf-like in duck, T-shape in goose and appeared as very small bulla in dove as well as it was $\mathrm{C}$ shape enclosed vertical lamella of the nostril in quail. The middle one scroll one and one-half turns in duck, two turns in goose, one-half turn in quail and absent in dove. The caudal nasal concha in duck, goose, and quail was bulla-like and hollow pear-shaped in dove. The infra-orbit sinus was well developed in the aquatic birds than that of the non-aquatic birds.
\end{abstract}

Keywords: Aquatic birds, Concha, Nasal cavity, Non-aquatic birds.

DOI: $10.21608 /$ svu.2019.14982.1022

Received: July 19, $2019 \quad$ Accepted: August 08, 2019

Published: August 16, 2019

*Corresponding Author: Fatma A. Madkour

E-mail:madkour.f@vet.svu.edu.eg

Citation: Madkour, Anatomical Descriptions of the Nasal Cavity of the Aquatic and Non-Aquatic Birds. SVU-IJVS 2019, 2 (2): 101-110.

Copyright: (C) Madkour. This is an open access article distributed under the terms of the creative common attribution license, which permits unrestricted use, distribution and reproduction in any medium provided the original author and source are created.

Competing interest: The authors have declared that no competing interest exists. 


\section{Introduction}

The nasal cavity of the different types of avian species like domestic fowl (McLelland,1990), Denizli cock (Taşbaş et al.,1994) and domestic ducks (Das,1965) has been well illustrated. The general shape of the nasal cavity is conical with a range of deviation according to the modifications of the beak (King,1975). In the domestic fowl and pigeon, the nasal cavity is bounded dorsally by the frontal process of the premaxilla bone, the intermaxillary process of the nasal bone and the lacrimal bone. The ventral aspect of the nasal cavity is formed by the maxillary process of the premaxilla bone (rostrally) and the palatine bone (caudally) while laterally bordered by the maxillary process of the nasal bone (Casteleyn et al., 2018). The nasal cavity extends from external nares to the choanal slit, containing conchae and meatuses implying homology to those of the mammals and other vertebrates (Bang and Wenzel,1985). The nostrils of some birds are covered by an operculum (Harte,1989), which may be a membranous, horny or cartilaginous (Whitney and Smith,1913).

There are three turbinate bones (conchae), the middle turbinate, called a true turbinate (Nemours, 1930) and rostral as well as caudal turbinate (pseudoturbinate type) as reported by Hodges (1974). Most birds have rostral (or anterior / ventral) and middle (or maxillary) conchae, with additional caudal (or posterior) concha in some species (Bang and Wenzel,1985, King,1993, Yokosuka et al.,2009). The nasal septum and conchae within the nasal cavity direct the influx of air towards the choanal slit (ventrally) and caudally to enter the maxillary sinus (Dabvp, 2015).

The function of avian nasal cavity is olfaction which aids in recognition of the individual's own nest and its occupants, humidification of the inspired air (King,1975), air filtration, water preservation and thermoregulation (Dabvp,2015). The identification of food material with olfactory sense is also reported in some birds (Harriman and Berger, 1986). The rostral and maxillary conchae help in heat exchange and air conditioning whereas the caudal and maxillary conchae perform olfactory function in several species (Murrish, 1973). To our knowledge, there was a shortage of information concerning the nasal cavity in some birds as laughing doves and Egyptian geese. So, this work interested to describe the morphometrical and anatomical features of the nasal cavity of the aquatic and non-aquatic birds.

\section{Materials and Methods}

The present investigation was carried out on two species of aquatic birds (Muscovy ducks and Egyptian geese) and two species of non-aquatic bids (laughing doves and Japanese quails). The total number of the birds was 16 healthy adult birds, divided into four groups for each species (both sexes). Muscovy ducks were collected from local farms in Assiut Governorate, Egyptian geese were obtained from local Market in the Egyptian villages of Qena Governorate, and Laughing doves were trapped from bird hunters in Qena Governorate while Japanese quails were obtained from researcher's farm in South Valley University.

All birds were slaughtered and completely bled then the heads were dissected from the bodies and washed with distilled water and saline. The heads were sectioned in a sagittal manner and also sectioned transversally at the level of the rostral, middle, caudal nasal regions. The examined features of the nasal cavity were photographed using phone camera (Oppo 
F7). The different measurements of the nasal cavity and its ingredients of each bird were measured separately by a digital caliper in millimeters. The mean value \pm standard error $(S E)$ was used.

\section{Results}

The present study revealed that the nasal cavity was opened externally by nostrils which were located at the base of the upper beak at variable distances viz. $15.06 \pm 0.58,26.86 \pm 0.97,3.93 \pm 0.02 \mathrm{~mm}$ in duck, goose and dove respectively but in quail, it was located punctually at the base of the beak (Fig.1A-1D).

The nostrils were without operculum and elliptical with thickened rim in duck and oval in goose so the rostral end of the ventral concha could be seen through it (Fig.1A, and 1B). While the nostrils were elongated slit-like and covered with horny structure, the operculum in dove and quail. The operculum was wider rostrally and directed obliquely from culmen to the lateral edges of the upper beak in dove and vertically oriented in quail (Fig.1C, and 1D).

The length of the nostril in the aquatic birds was $6.93 \pm 0.03 \mathrm{~mm}$ in duck and $8.72 \pm 0.57 \mathrm{~mm}$ in goose. The averages of the nostril lengths in aquatic birds were more than those of the non-aquatic birds which measured $3.11 \pm 0.10 \mathrm{~mm}$ in dove and $4.07 \pm 0.12 \mathrm{~mm}$ in quail. Similarly, the diameter of the nostril was wider in the aquatic birds $(2.75 \pm 0.06 \mathrm{~mm}$ in duck and $3.79 \pm 0.41 \mathrm{~mm}$ in goose) than in the nonaquatic birds $(0.88 \pm 0.08 \mathrm{~mm}$ in dove and $0.99 \pm 0.08 \mathrm{~mm}$ in quail). The nasal cavity in all the examined species was mainly conical in shape and it measured $35.22 \pm 0.63,44.63 \pm 3.02,13.02 \pm 0.67$, and
$11.53 \pm 0.22 \mathrm{~mm}$ long in duck, goose, dove, and quail, respectively. The width of the nasal cavity showed a gradual increase caudally.
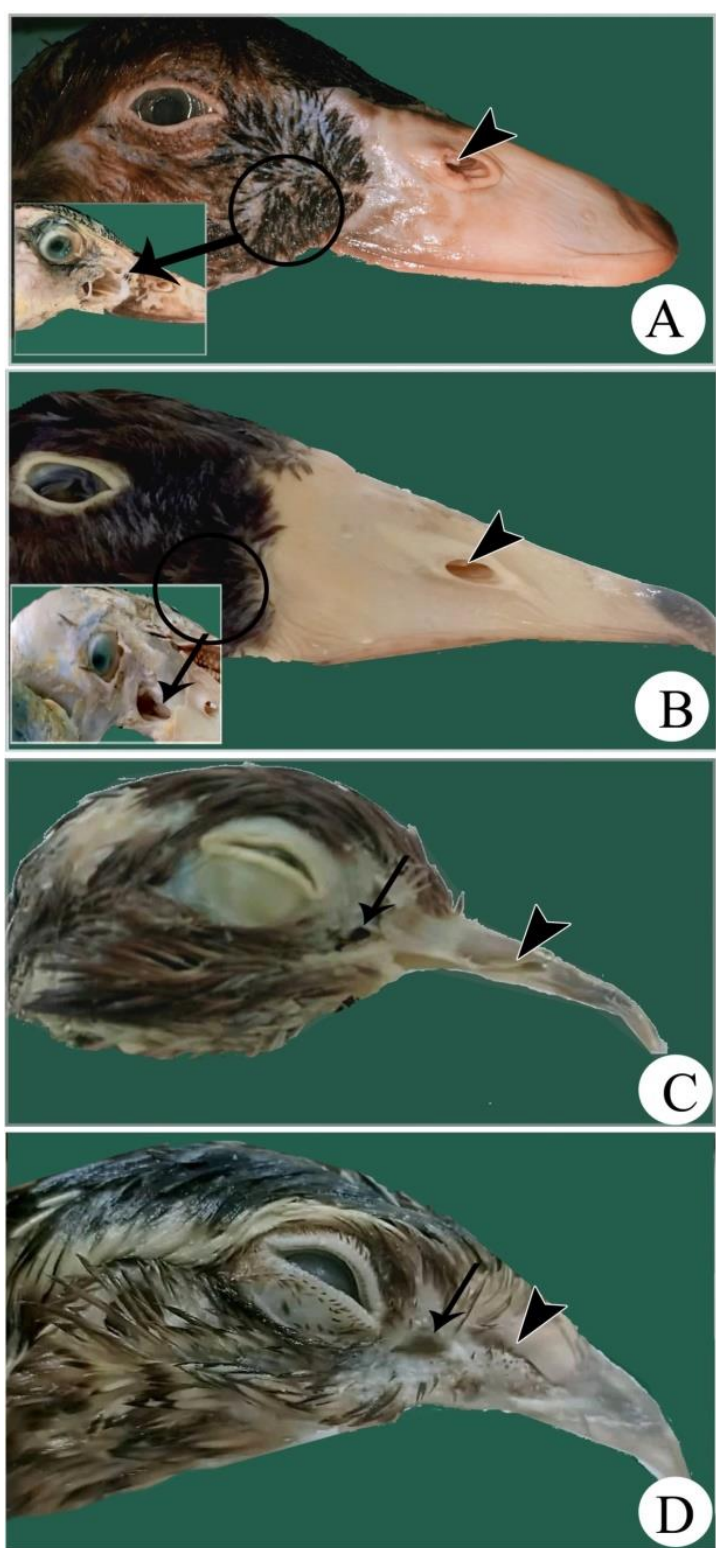

Fig. 1. Photographs of the upper beak of duck (A), goose (B), dove (C) and quail (D) showing nostril (arrow head), infraorbital sinus (arrow). 
The measurements at the rostral vestibule, middle respiratory and caudal olfactory regions were 5.99 \pm 0.98 , $12.14 \pm 1.42, \quad 17.90 \pm 1.27 \mathrm{~mm}$ in duck, $5.69 \pm 0.28,17.52 \pm 1.16,21.04 \pm 1.67 \mathrm{~mm}$ in goose, $2.48 \pm 0.29, \quad 3.41 \pm 0.02, \quad 5.97 \pm 0.10$ $\mathrm{mm}$ in dove and $3.77 \pm 0.17,5.41 \pm 0.25$, $7.17 \pm 0.32 \mathrm{~mm}$ in quail, respectively (Fig. 2A-2D). The increase of the width of the nasal cavity caudally was obvious in goose than duck and in quail than dove. The nasal septum divided the nasal cavity (longitudinally) into right and left halves, which was composed by cartilaginous plate in the non-aquatic birds but rostral cartilaginous and caudal bony plate in the aquatic birds. Moreover, in the aquatic birds, both the halves were communicated rostrally (opposite to the nostril) with each other by an elongated and elliptical perforation in the nasal septum (Fig. 2A, and $2 \mathrm{~B}$ ). The length of the opening was $8.59 \pm 0.96,10.04 \pm 0.23 \mathrm{~mm}$ while the width was $2.38 \pm 0.13,2.96 \pm 0.30 \mathrm{~mm}$ in duck and goose, respectively. The nasal cavity was consisted of three nasal conchae viz. rostral, middle and caudal nasal conchae in all examined birds, except dove, which had two conchae as ill developed rostral and well-developed caudal nasal conchae (Fig. 2A-2D). The length of the rostral, middle, caudal conchae was 12.41 \pm 1.17 , $22.51 \pm 1.25, \quad 10.47 \pm 0.44 \mathrm{~mm}$ in duck; $17.15 \pm 0.34,24.63 \pm 1.74,8.17 \pm 0.77 \mathrm{~mm}$ in goose; and $4.35 \pm 0.21,6.79,2.88 \pm 0.14 \mathrm{~mm}$ in quail, while in dove, the length of the rostral concha was $3.80 \pm 0.19 \mathrm{~mm}$ and of the caudal one was $5.49 \pm 0.19 \mathrm{~mm}$. The rostral concha in the aquatic birds was elongated, its rostral end more curved in duck so it has seen clearly through the nostril in duck than goose, while the caudal end of the concha attached to the floor of the nasal cavity by a fold (Fig. 2A, and $2 \mathrm{~B})$. The length of the rostral concha was $12.41 \pm 1.17 \mathrm{~mm}$ in duck and 17.15 \pm 0.34 $\mathrm{mm}$ in goose.

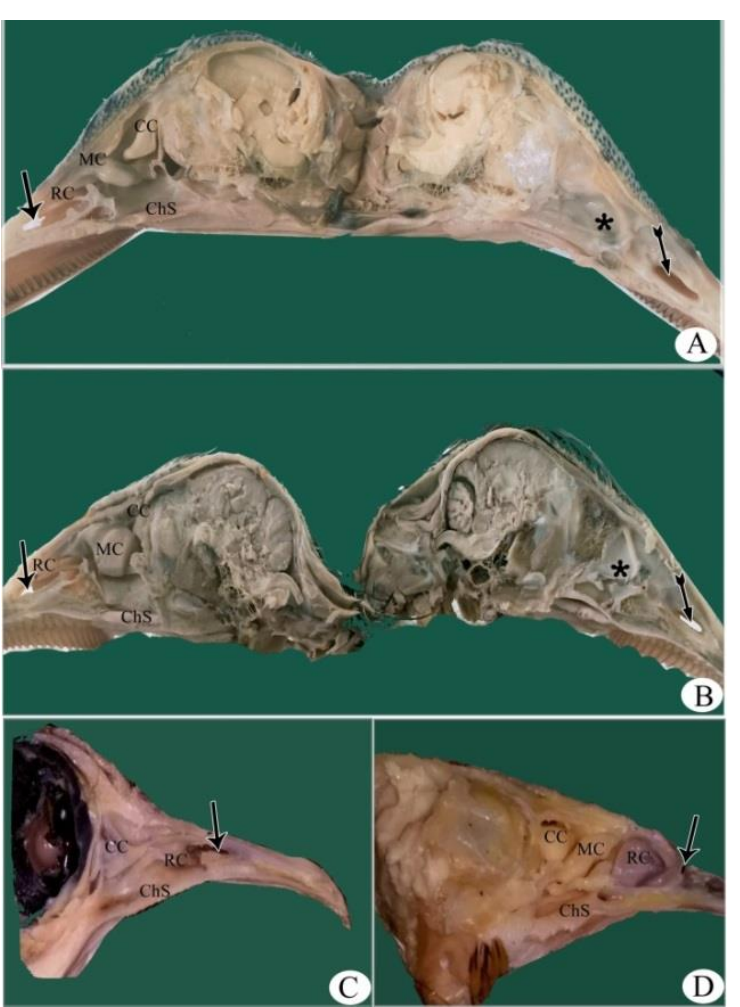

Fig. 2. Photographs of the sagittal sections of the nasal cavity of duck (A), goose (B), dove (C) and quail (D) showing nostril (arrow), nasal septum (star) perforating by opening (barbed arrow), rostral (RC), middle (MC), caudal (CC) nasal conchae, choanal slit (ChS).

In transverse sections, the rostral concha appeared as a shelf-like in duck and as Tshape in goose projected from the lateral wall of the nasal cavity related dorsally by cranial end of the middle nasal concha in duck (Fig. 3A, and 3B). In dove, the rostral concha was a tiny structure extended caudally and ventral to the caudal concha whereas in quail, it was pyramidal in shape and its base was directed craniodorsally, towards the roof of the nasal cavity and its apex was directed caudo-ventrally, towards the floor of the nasal cavity (Fig. 2C, and 2D). Its length was measured $3.80 \pm 0.19$ $\mathrm{mm}$ in dove and $4.35 \pm 0.21 \mathrm{~mm}$ in quail. In transverse sections, the rostral concha was C shape enclosed vertical lamella of the 
nostril in quail but not well distinct in dove and which was appeared as very small bulla beneath the caudal one (Fig. 3C, and 3D).

The middle concha was the largest in duck, goose and quail but absent in dove. In duck, it was largely elongated with its narrower cranial end attached to the dorsal wall of the nasal cavity and the wider caudal end directed toward the choanal slit and it was measured $22.51 \pm 1.25 \mathrm{~mm}$ in length and represented $63.91 \%$ of the nasal cavity. While in goose, the middle concha was large pear shaped with its apex directed cranially and base directed caudoventrally towards the choanal slit and it was measured $24.63 \pm 1.74 \mathrm{~mm}$ long representing $58.88 \%$ of the nasal cavity (Fig. 2A, and 2B). In quail, the middle concha resembled that of duck (Fig. 2D) and it measured $6.79 \mathrm{~mm}$ long, constituting $58.88 \%$ of the nasal cavity.

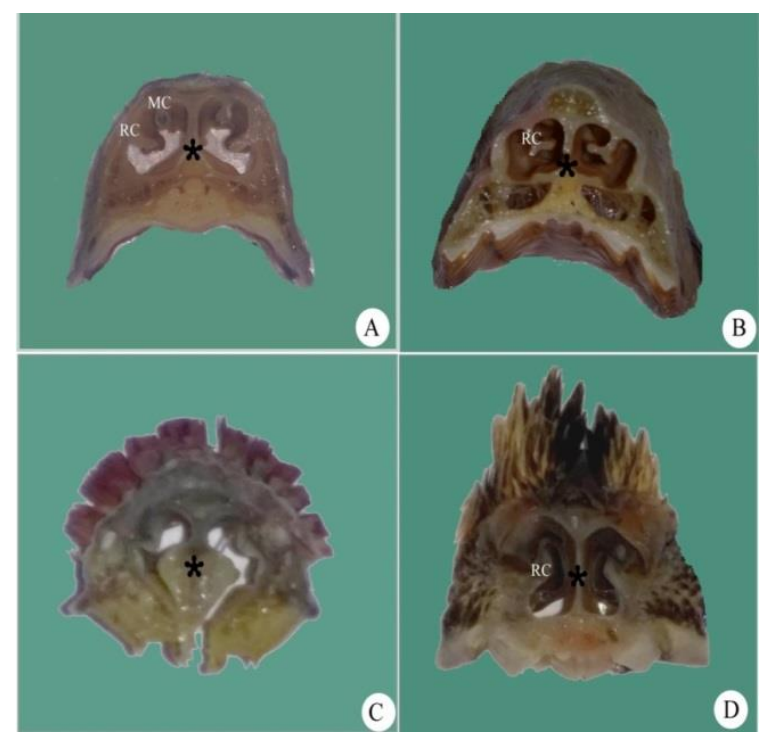

Fig. 3. Photographs of the transverse sections of the nasal cavity at level of rostral vestibular region of duck (A), goose (B), dove (C) and quail (D) showing rostral (RC), middle (MC) nasal conchae, nasal septum (star).

In transverse sections, the middle concha was scrolled ventrolaterally with one and one-half turns in duck, two turns in goose and one-half turn in quail (Fig. 4A-4C). The caudal concha was the smallest one among all examined birds except dove, which was the largest one. It was narrow elongated triangle shaped in duck, compressed triangle closely related to the middle one in goose and hemispherical and located caudodorsally to the middle one in quail (Fig. 2A, 2B, and $2 \mathrm{D})$. The caudal concha was measured $10.47 \pm 0.44, \quad 8.17 \pm 0.77, \quad 2.88 \pm 0.14 \mathrm{~mm}$ long in duck, goose, and quail, respectively. In dove, the caudal concha occupied the most olfactory region and extended to respiratory region; it was sugar scoop-like with pointed cranial end directed towards the nostril and roof of the nasal cavity and the wide caudal end located in front of the orbit (Fig. 2C). Its length was $5.59 \pm 0.19 \mathrm{~mm}$, representing $42.16 \%$ of the nasal cavity. In transverse sections, in all birds except dove, it was bulla-like and not connected with the nasal cavity but connected with infraorbital sinus. However, in dove, the caudal concha was a hollow pear-shaped with ventral narrow and dorsal wide parts (Fig. 5A-5D). The infraorbital sinus was well developed in the aquatic birds in comparison with that of the non-aquatic birds. The sinus was located rostro-ventral to the eyeball by variable distances i.e. $4.92 \pm 0.65$, $9.17 \pm 0.84,2.73 \pm 0.14$, and $1.5 \pm 0.07 \mathrm{~mm}$ in duck, goose, dove and quail, respectively. The infraorbital sinus was a triangle shaped in all examined birds; with large rostral end in duck and with a large caudal end in goose, boundary dorsally by a groove of the nasolacrimal duct which located on the lateral aspect of lacrimal bone (Fig. 1A-1D). The cranio-caudal diameter of the sinus was $13.58 \pm 0.60 \mathrm{~mm}$ in duck, $17.01 \pm 0.97 \mathrm{~mm}$ in goose, $2.37 \pm 0.43 \mathrm{~mm}$ in dove and $2.39 \pm 0.24 \mathrm{~mm}$ in quail. 


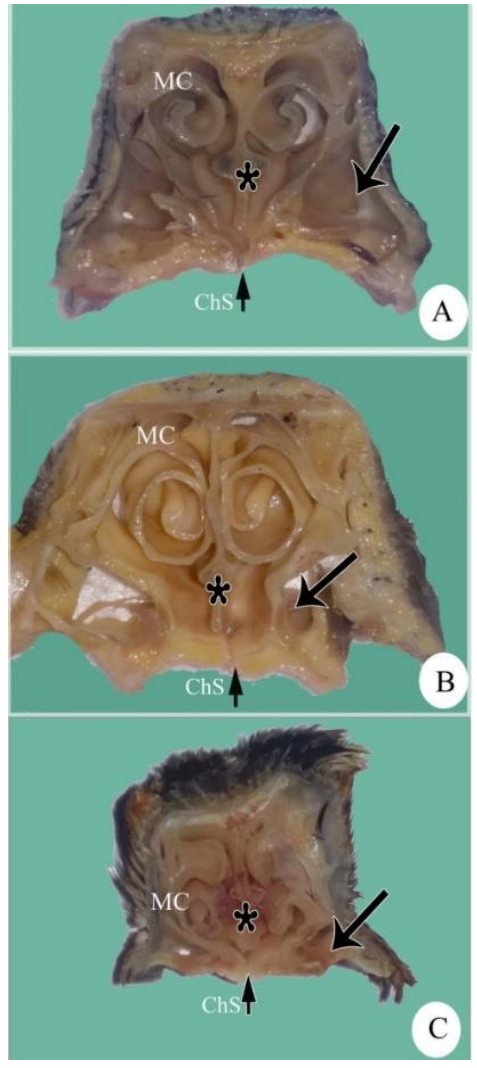

Fig. 4. Photographs of the transverse sections of the nasal cavity at level of the middle respiratory region of duck (A), goose $(\mathrm{B})$, and quail $(\mathrm{C})$ showing middle (MC) nasal concha, nasal septum (star), choanal slit (ChS), infraorbital sinus (arrow).

\section{Discussion}

As in most bird species, the external nares (nostrils) were located at the base of the upper beak but by variable distances in examined birds $15.06 \pm 0.58,26.86 \pm 0.97$, $3.93 \pm 0.02 \mathrm{~mm}$ in duck, goose, and dove respectively while in quail, it was situated exactly at the base of the beak. In contrast they were located at the tip of their upper beak in Kiwis, (Stettenheim,2000). Some water birds e.g. Cormorants, boobies and darters do not have nostrils, so they breathe

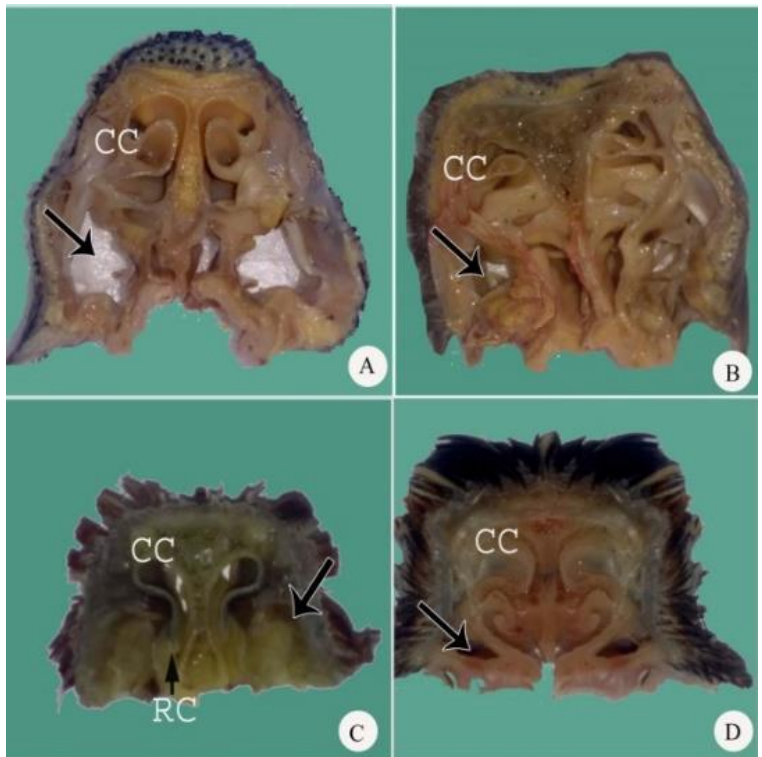

Fig. 5. Photographs of the transverse sections of the nasal cavity at level of the caudal olfactory region of duck (A), goose (B), dove(C) and quail (D) showing rostral (RC), caudal (CC) nasal conchae, infraorbital sinus (arrow).

through their mouths (Wilson and Burnie, 2001). Moreover, tube-nosed birds (order Procellariformes) have nostrils enclosed in double tubes located along the sides of the upper jaw or fused at the top of the beak (Chester,2010). Corresponding to the shape, the nostrils were oval without operculum in goose as mentioned in turkey by Sayed et al. (2014) and in ostrich by Ali (2015), elliptical without operculum in duck and elongated slit-like reduced in size due to the horny operculum in dove and quail. However, the nostrils of hooded crow were circular in shape and were covered by a tuft of feathers (Hassan, 2012), which warms the inhaled air (Gellhorn, 2007). On the other hand, in falcon, the covering of the nostrils was osseous tubercula, which slows down the passage of the air into the nostrils 
(Stettenheim, 2000). Tudge (2009) added that the opercula of two species of Attagis seedsnipe prevent entrance of dust into the respiratory passages. In the chicken, two cartilaginous plates (dorsal and ventral) enclose the nostrils (Casteleyn et al., 2018). The current study clarified that the nasal septum was cartilaginous in the non-aquatic birds but cartilaginous (rostrally) and bony (caudally) in the aquatic birds. The results of the nonaquatic birds agreed with reports in chicken and pigeon (Casteleyn et al., 2018) while of the aquatic birds with reports by Altman et al. (1960) but in contrast with earlier reports in duck by Kang et al. (2014) where the septum was cartilaginous. In addition, the nasal septum was membrano-cartilaginous (rostrally) and bony (caudally) in ostrich (Ali, 2015). Our study added that the nasal septum was perforated by an elongated elliptical opening to allow the passage of water outside the nasal cavity during diving. On the contrary, with reference to the previously studied birds the nasal septum was absent in new world vulture (Allaby, 1991). In regards to the nasal conchae, there were three nasal conchae; rostral, middle, caudal in duck, goose, quail which were similar to the observations in ostrich (Jin et al., 2008, Ali, 2015), in quail (Fitzgerald,1969, Cevik-Demirkan et al., 2007) and the domestic chicken (Bang and Wenzel, 1985). The present findings in dove as only two conchae viz. rostral and caudal conchae with the ill-developed rostral concha was agreed with the observations of Hassan (2012) in hooded crow and Kang et al. (2014) in duck. Furthermore, Casteleyn et al. (2018) mentioned in chicken, pigeon, and McLelland (1990) in quail that the rostral concha is absent. However, the caudal nasal concha was indistinct in Japanese jungle crow (Yokosuka et al., 2009) and absent in some Falconiformes and swifts
(King and McLelland,1984), in Song Sparrow (Danner et al., 2017), in some species as Collocolia (Bang, 1971) and Psittacus (Pohlmeyer and Kummerfeld, 1989).

The examined aquatic birds had relatively larger nasal conchae and greater of the middle nasal concha than the nonaquatic birds which was corroborative with Van Valkenburgh et al. (2011) who hypothesized that the aquatic and semi earthy mammals have relatively larger respiratory conchae than their earthy mammals. The larger surface area of the conchae allows greater water condensation during expiration to ameliorate water efficiency and improves water conservation (Danner et al., 2017). So the current statistical data clarified that the middle nasal conchae length constituted the highest percentage to that of the nasal cavity which recorded $63.91 \%, 55.18 \%$, and $58.88 \%$ in duck, goose, and quail, respectively was in accordance with reports of King and McLelland (1984) in domestic birds, Kang et al. (2014) in duck and Yokosuka et al. (2009) in Japanese jungle crow. While the caudal concha in the dove had recorded the highest percentage $(42.16 \%)$ of the nasal cavity, which was contrary with Fitzgerald (1969) in quail, Doğuer and Erençin (1964) and Nickle et al. (1977) in pigeon who illustrated that the caudal concha is the smallest however they coincided with the findings in the other birds examined in present study.

In the current study, the rostral conchae was shelf-like in duck, T-shape in goose projecting from the lateral wall of the nasal cavity were in agreement with Ali (2015) in ostrich and King and McLelland (1984) in domestic fowl. In addition, it was appeared as $\mathrm{C}$ shape enclosed vertical lamella of nostril in quail, which was similar to the reports of CevikDemirkan et al. (2007) in quail and Hassan 
(2012) in hooded crow. Analogous to the descriptions reported for of the other species, the middle concha had the ideal scroll-like form which completed one and one-half turns in duck, 2 turns in goose and one-half turn in quail. The middle concha scroll takes two turns in domestic birds (Bittner,1925), one-half in quail (CevikDemirkan et al., 2007), coiled bulla-like in ostrich (Ali, 2015) and as whelk shell in duck (Kang et al., 2014). Corresponding to the caudal concha was bulla shaped in all examined birds except dove which was hollow pear-shaped with ventral narrow and dorsal wide part. In contrast, it turns one and half in hooded crow (Hassan, 2012) and scroll-like closely attached with the middle one in ostrich (Ali,2015). This study documented that the infraorbital sinus was well developed and triangle shaped in the aquatic birds in comparison with the non-aquatic birds. The sinus was broad in duck and goose but narrow in fowl (Casteleyn et al., 2018). Moreover, the infraorbital sinus is a single in birds situated on each side of the head, communicates caudo-dorsally with the nasal cavity (Dabvp, 2015).

\section{Conclusion}

In conclusion, this work clarified that the nostrils were without operculum in the aquatic and with operculum in the aquatic birds. The aquatic birds had relatively larger nasal conchae and infraorbital sinus than the aquatic birds as well as the scrolling of the conchae was more in the aquatic birds and compared with other different habit birds.

\section{Acknowledgement}

The author would express deepest gratitude and thankfulness to the bird hunters and the workers at the researchers' farm in South Valley University for their efforts in trapping birds to complete this work.

\section{Conflict of interest statement}

The authors declare that they have no conflict of interest.

\section{References}

Ali S (2015). Gross anatomical studies on the nasal cavity of the ostrich. Benha Veterinary Medical Journal, 29(2): 326-332.

Allaby M. (1991). The concise Oxford dictionary of zoology. Ed. by Michael Allaby.Oxford - New York,Oxford Univ P VI.

Altman RB, Clubb SL, Dorrestein GM, Quesenberry K (1960). Avian medicine and surgery. Philadelphia, WB Saunders, 387-390.

Bang B, and Wenzel B (1985). Nasal cavity and olfactory system. Form and function in birds, 3: 195-225.

Bang BG (1971). Functional anatomy of the olfactory system in 23 orders of birds. Acta anatomica, 79: 1-76.

Bittner H (1925). Nasenböhle und ihre Nebenböhle belm Hausgeflügel. Berl., 41: 576-579.

Casteleyn C, Cornillie P, Van Cruchten S, Van den Broeck W, Van Ginneken, C, Simoens P (2018). Anatomy of the upper respiratory tract in domestic birds, with emphasis on vocalization. Anatomia, histologia, embryologia, 47(2): 100-109.

Cevik-Demirkan A, Kürtül I, Haziroğlu RM (2007). Gross morphological features of the nasal cavity in the Japanese quail. Ankara Universitesi Veteriner Fakültesi Dergisi, 50(1): 1.

Chester S (2010). A Wildlife Guide to Chile: Continental Chile, Chilean Antarctica, Easter Island, Juan Fernandez Archipelago, Princeton University Press. 
Dabvp LPD (2015). Avian respiratory medicine CVC In Washington, D.C. Proceedings.

Danner RM, Gulson-Castillo ER, James HF, Dzielski SA, Frank DC, Sibbald ET, Winkler DW (2017). Habitat-specific divergence of air conditioning structures in bird bills. The Auk The Auk, 134(1): 65-75.

Das L (1965). Comparative anatomy of the domestic duck. Indian Veterinary, 42: 320-326.

Doğuer S and Erençin Z (1964). Evcil kuslarin komparativ anatomisi. Ankara, Ankara Universitesi Veteriner Fakültesi.

Fitzgerald TC (1969). The coturnix quail; anatomy and histology. Ames, Iowa State University Press.

Gellhorn J (2007). White-tailed Ptarmigan: ghosts of the alpine tundra, Big Earth Publishing.

Harriman AE and Berger RH (1986). Olfactory acuity in the common raven (Corvus corax). Physiology \& behavior, 36(2): 257-262.

Harte J (1989). The Birder's Handbook: A Field Guide to the Natural History of North American Birds. BioScience, 39(7): 492-494.

Hassan S (2012). Gross anatomical features of the nasal cavity of the hooded crow (Corvuscornix). SCVMJ, XVII 2: 119-127.

Hodges RD (1974). The histology of the fowl, Academic Press.

Jin EH, Peng KM, Wang JA, Du AN, Tang L, Wei L, Wang Y, Li SH, Song H (2008). Study of the Morphology of the Olfactory Organ of African Ostrich Chick. Anatomia Histologia Embryologia, 37(3): 161-165.

Kang H, Yan M, Yu Q, Yang Q (2014). Characterization of Nasal CavityAssociated Lymphoid Tissue in
Ducks. The Anatomical Record, 297(5): 916-924.

King AS (1975). Aves respiratory system. In: Getty, R. (ed.). Sisson and Grossman's the anatomy of the domestic animals. W.B. Saunders Co., Philadelphia and London.

King AS (1993). Apparatus respiratorius (systema respiratorium). Handbook of avian anatomy: nomina anatomica avium. Cambridge, MA: Nuttall Ornithological Club. p: 257299.

King AS and McLelland J (1984). Birds, their structure and function,Bailliere Tindall, $1 \mathrm{St}$. Annes Road.

McLelland J (1990). A colour atlas of avian anatomy, Wolfe Medical Publications Ltd.

Murrish DE (1973). Respiratory heat and water exchange in penguins. Respiration physiology, 19(3): 262270.

Nemours $P$ (1930). Studies on the accessory nasal sinuses: The comparative morphology of the nasal cavities of reptiles and birds. Ann. Otol. Rhinol. Laryngol 39: 1086-1108.

Nickle R, Schummer A, Seiferle E (1977). Anatomy of the domestic bird. Translated by SILLER, WG and PA WIGHT. Verlag, Paul Parey, Berlin: 72-75.

Pohlmeyer K and Kummerfeld N (1989). Morphologie der Nasenhöhle und der nasen Nebenhöhlen sowie ihre klinische Bedeutung bei Grosspapageien. Kleintierpraxis, 34: 127-133.

Sayed RK, Abdalla KE, Ahmed AK, Saleh AM (2014). Morphological studies on the upper beak of Turkey (Meleagris gallopavo). Journal of Advanced Veterinary Research, 4(4): 154-160. 
Stettenheim PR (2000). The integumentary morphology of modern birdsan overview. American Zoologist, 40(4): 461-477.

Taşbaş M, Hazıroğlu R, Çakır A, Özer M (1994). Denizli horozunun solunum sisteminin morfolojisi I. Cavitas nasalis. Ankara Univ Vet Fak Derg, 41: 63-80.

Tudge C (2009). The bird:A natural history of who birds are, where they came from, and how they live, Crown.

Van Valkenburgh B, Curtis A, Samuels JX, Bird D, Fulkerson B, MeachenSamuels J, Slater GJ (2011). Aquatic adaptations in the nose of carnivorans: evidence from the turbinates Aquatic adaptations in the nose of carnivorans. Journal of Anatomy, 218(3): 298-310.
Whitney WD and Smith BE (1913). The Century dictionary and cyclopedia: with a new atlas of the world: a work of general reference in all departments of knowledge,Century Company.

Wilson DE and Burnie D (2001). "Pelicans and relatives birds" in Animal: the definitive visual guide to the world's wildlife.Dorling Kindersley, London, UK. .

Yokosuka M, Hagiwara A, Saito TR, Tsukahara N, Aoyama M, Wakabayashi Y, Sugita S, Ichikawa M (2009). Histological properties of the nasal cavity and olfactory bulb of the Japanese jungle crow Corvus macrorhynchos. Chem Senses, 34(7): 581-593. 